\title{
Supercooled liquid water cloud observed, analysed, and modelled at the top of the planetary boundary layer above Dome C, Antarctica
}

\section{Philippe Ricaud et al.}

Correspondence to: Philippe Ricaud (philippe.ricaud@meteo.fr)

The copyright of individual parts of the supplement might differ from the CC BY 4.0 License. 


\section{Ten-day back-trajectories}

Ten-day back-trajectories originated from the Dome $\mathrm{C}$ station at 500 and $1000 \mathrm{~m}$ above ground level have been calculated on 20 and 24 December 2018 at 12:00 UTC (Figures S1) from the Hybrid Single-Particle Lagrangian Integrated Trajectory model (HYSPLIT) model (Stein et al., 2015; Rolph et al., 2017) (https://www.ready.noaa.gov/HYSPLIT.php). Trajectories are initiated from the Antarctic continent during the typical case of 24 December 2018 whilst, during the perturbed case of 20 December 2018, they are initiated from the oceanic Antarctic Coast opposite in longitude to the Dome C station $\left(0-30^{\circ} \mathrm{W}\right)$. This perturbed case brings warm and wet oceanic airmasses to the Dome $\mathrm{C}$ station atmosphere consistently to what has already been observed and analysed above the Dome $\mathrm{C}$ station during episodes of thick clouds in March 2011 and 2013 (Ricaud et al., 2017).

\section{Solid precipitation from ARPEGE-SH}

The diurnal variation along the vertical of the Total Snow Flux $\left(\mathrm{mm} \mathrm{day}^{-1}\right)$ calculated by ARPEGE-SH on 24 December 2018 and on 20 December 2018 is shown on Figures S2 and S3, respectively. On 24 December 2018 (Fig. S2), ARPEGE-SH forecasts some solid precipitation between 00:00 and 10:00 UTC from $\sim 500 \mathrm{~m}$ agl to the surface consistently with the LIDAR observations (Figs. 2a and b). On 20 December 2018 (Fig. S3), ARPEGE-SH calculates trace amounts of solid precipitation close to the surface around 16:00 UTC consistently with the LIDAR observations (Figs. 9a and b). ARPEGE-SH was thus able to forecast solid precipitation during the 2 case studies.

\section{CALIOP/CALIPSO observations}

Figures S4 and S5 represent the CALIOP/CALIPSO spaceborne LIDAR observations at $532 \mathrm{~nm}$ version V3.40 along one orbit on 24 December 2018 in the vicinity of Dome $\mathrm{C}\left(75^{\circ} \mathrm{S}\right.$, $\left.123^{\circ} \mathrm{E}\right)$ of: (a) the Total Attenuated Backscatter $\left(\mathrm{km}^{-1} \mathrm{sr}^{-1}\right)$ and (b) the Perpendicular Attenuated Backscatter $\left(\mathrm{km}^{-1} \mathrm{sr}^{-1}\right)$ at 15:50-16:03 UTC and 14:11-14:25 UTC, respectively.

Figures S6 and S7 represent the CALIOP/CALIPSO spaceborne LIDAR observations version V3.40 along one orbit in the vicinity of Dome $\mathrm{C}\left(75^{\circ} \mathrm{S}, 123^{\circ} \mathrm{E}\right)$ of: a) the Vertical Feature Mask highlighting a cloud (light blue) near the surface (red circle) and b) the Ice/Water Phase Mask highlighting a SLW (dark blue) cloud near the surface (red circle) on 24 December 2018 at 14:11-14:25 UTC and on 20 December 2018 at 13:17-13:31 UTC, respectively.

\section{4. $P$ and $S$ signals from the LIDAR}

For the two dates under consideration (Figures S8 and S9 relative to 24 and 20 December 2018 , respectively), we have represented (top) the $\mathrm{P}$ signal as the signal received with the same polarization as the laser (unpolarized component). Any suspended object can contribute to $\mathrm{P}$ signal. We have also represented the S (cross-polarized) LIDAR signal (bottom) that is only produced by non-spherical (obviously frozen at Dome C) particles and, to a smaller extent, by multiple scattering in water clouds.

\section{Impact of the ice partitioning function on SLW Clouds in ARPEGE-SH}

Figure S10 shows the Ice/Liquid Water partition as a function of temperature used in the ARPEGE-SH NWP operational model (black) and in the "test" modified version (red). For 24 December 2018, and consistently with Fig. 3, we have drawn on Fig. S11 the diurnal evolutions of different variables calculated by ARPEGE-SH-TEST: a) the Cloud Fraction, b) the Ice Water mixing ratio and c) the Liquid Water mixing ratio. Similarly, and consistently with Fig. 4, Figure 19 presents: a) the ARPEGE-SH-TEST TCI, b) the LWP measured by HAMSTRAD and calculated by ARPEGE-SH-TEST and c) the IWV measured by HAMSTRAD and 
calculated by ARPEGE-SH-TEST. Eventually, and consistently with Fig. 9, Figure S13 presents the net surface radiation observed by BSRN and calculated by ARPEGE-SH-TEST, and the difference between surface radiation of longwave downward, longwave upward, shortwave downward and shortwave upward components observed by BSRN and calculated by ARPEGE-SH-TEST. In the same manner, for the case of 20 December 2018, Figs. S12, 20 and S14 echo Figs. 11, 12 and 16, respectively. 


\section{Figures}
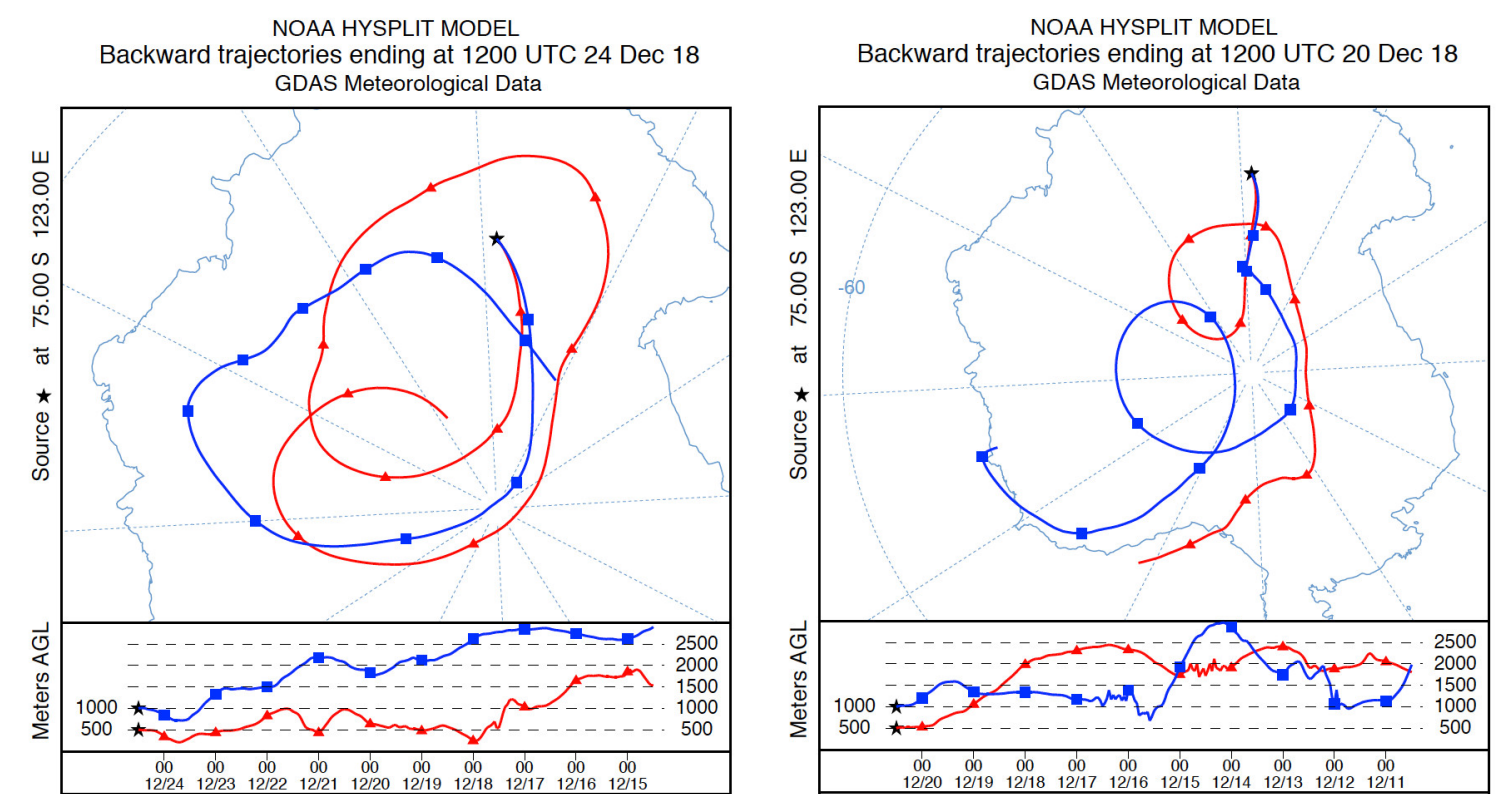

Figure S1: Ten-day backtrajectories calculated by HYSPLIT originated from the Dome C station at 500 (red) and $1000 \mathrm{~m}$ (blue) above ground level at 12:00 UTC on (left) 24 December 2018 (left, typical case study) and (right) 20 December 2018 (right, perturbed case study). 


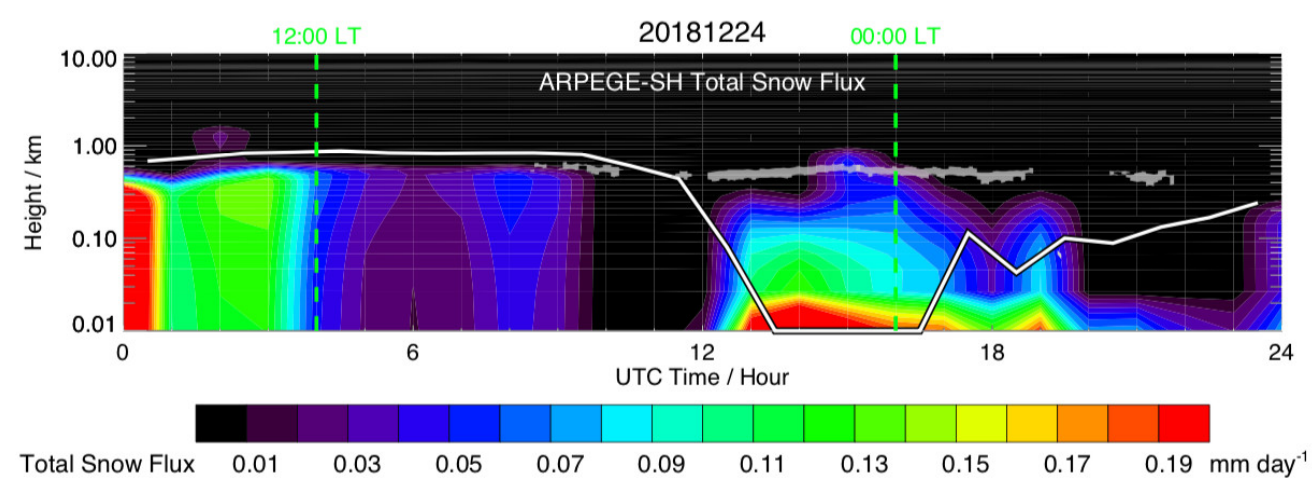

Figure S2: Time-height cross section on 24 December 2018 (UTC Time) of the Total Snow Flux (mm day ${ }^{-1}$ ) calculated by the ARPEGE-SH model. Superimposed is the top of the Planetary Boundary Layer calculated by the ARPEGE-SH model (black-white thick line) and the SLW cloud (grey area) deduced from the LIDAR observations (see Fig. 1c). Two vertical green dashed lines indicate 12:00 and 00:00 LT. 


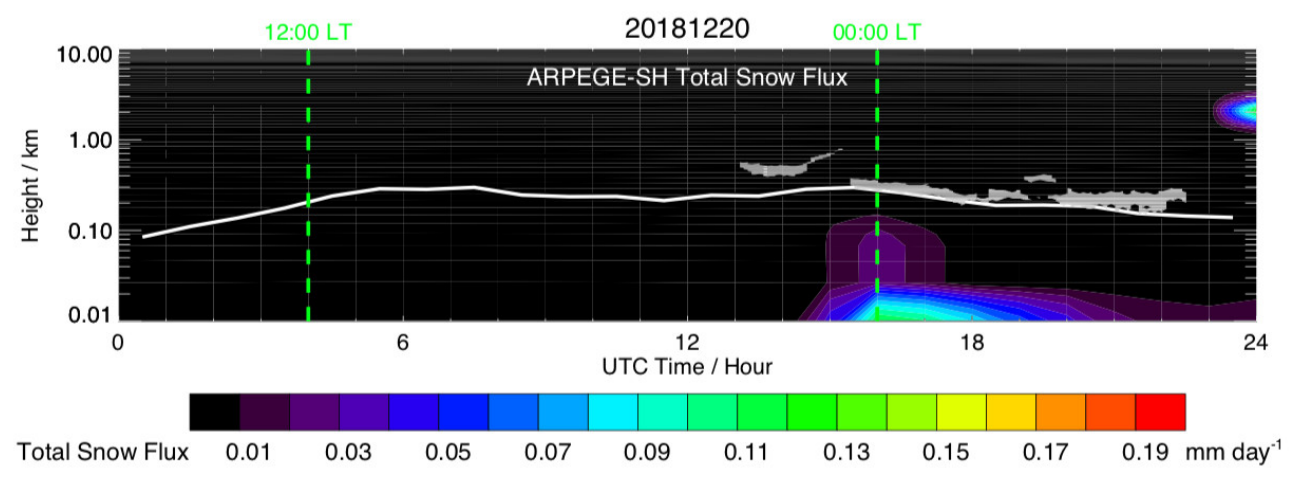

Figure S3: Same as Figure S2 but on 20 December 2018. 


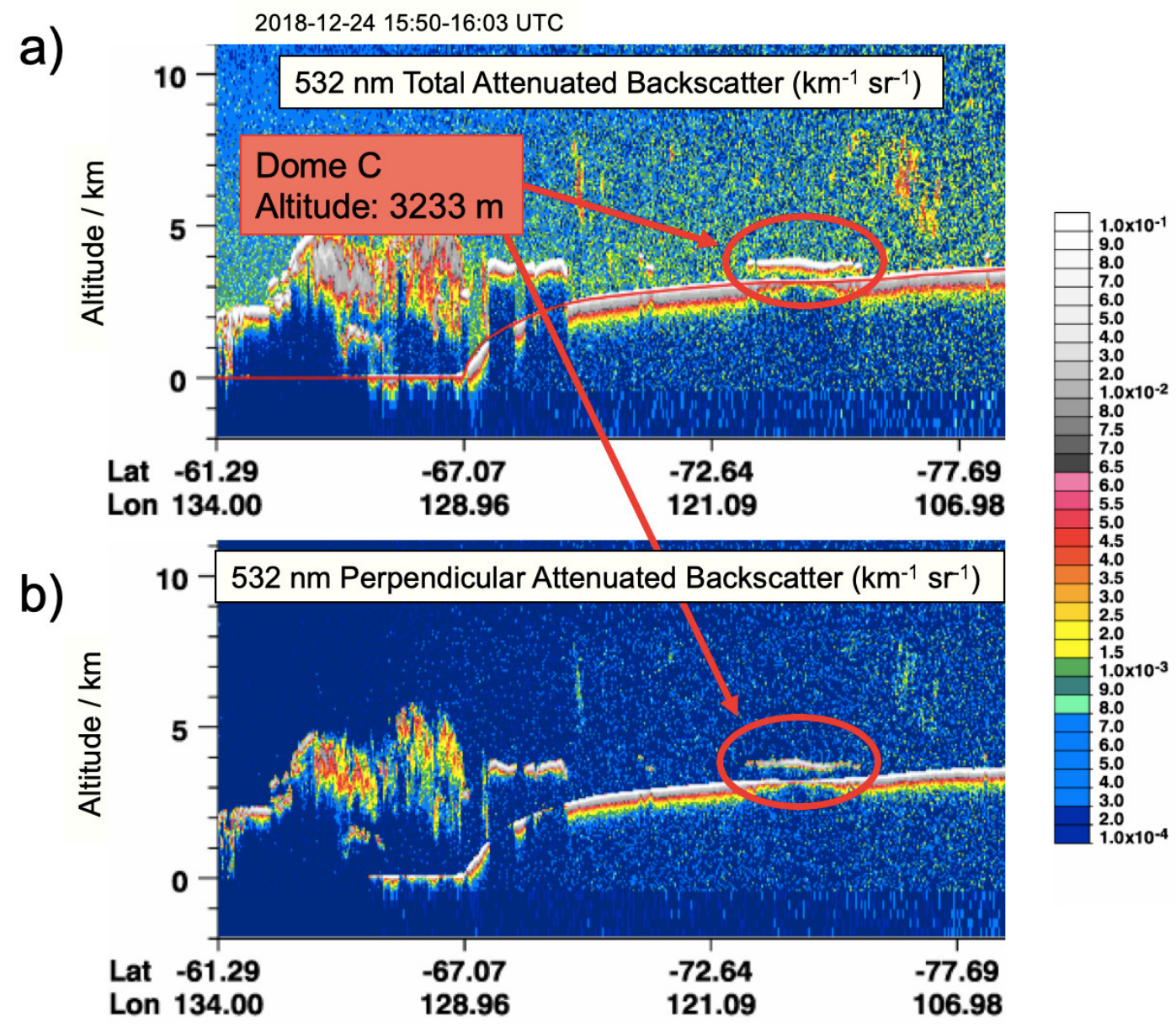

Figure S4: CALIOP/CALIPSO spaceborne LIDAR observations at $532 \mathrm{~nm}$ version V3.40 along one orbit on 24 December 2018 (15:50-16:03 UTC) in the vicinity of Dome $\mathrm{C}\left(75^{\circ} \mathrm{S}\right.$, $\left.123^{\circ} \mathrm{E}\right)$ of: (a) the Total Attenuated Backscatter $\left(\mathrm{km}^{-1} \mathrm{sr}^{-1}\right)$ and (b) the Perpendicular Attenuated Backscatter $\left(\mathrm{km}^{-1} \mathrm{sr}^{-1}\right)$. The red circle represents the cloud investigated in our analysis. 


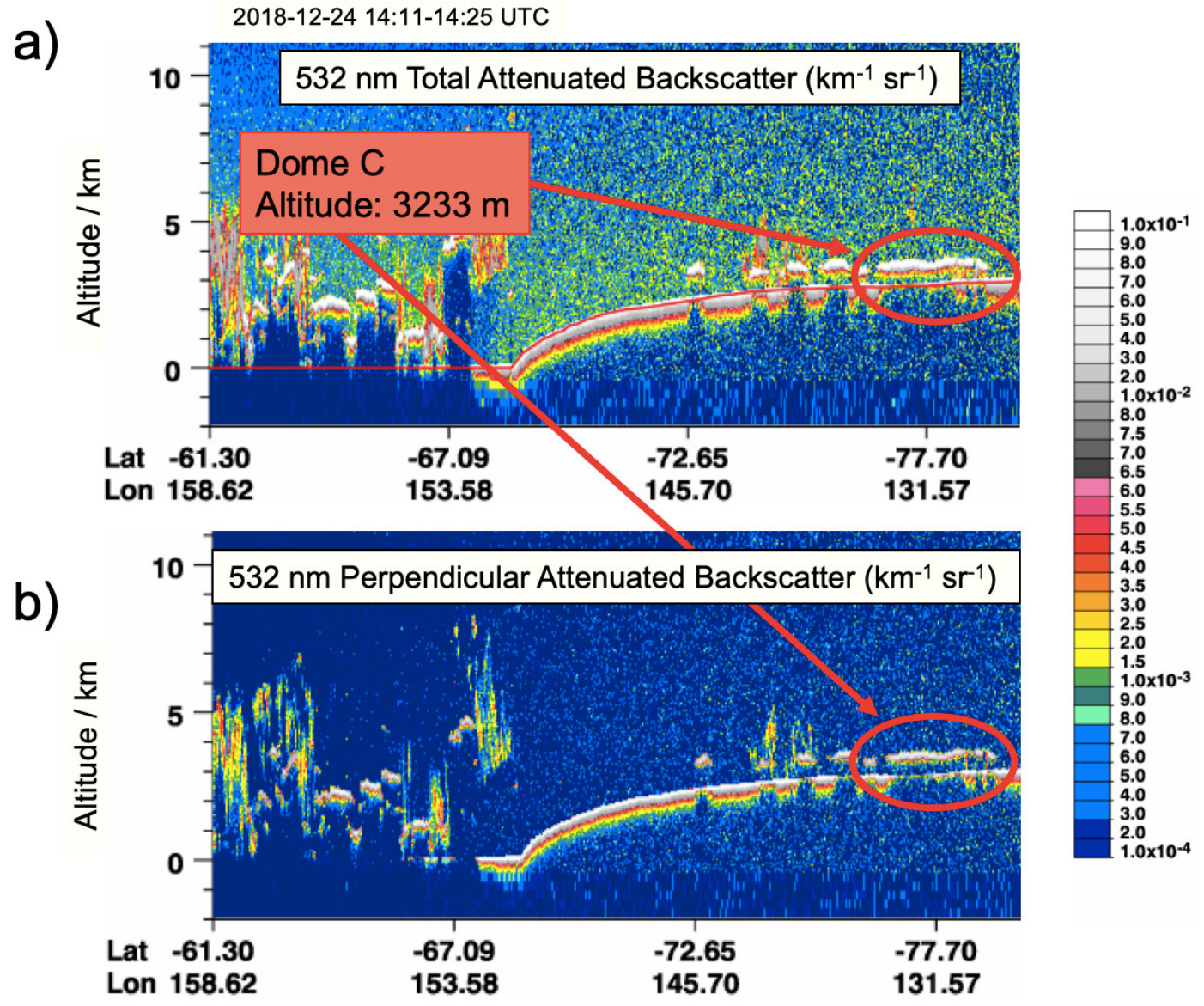

Figure S5: Same as Figure S4 but for one orbit on 24 December 2018 (14:11-14:25 UTC). 


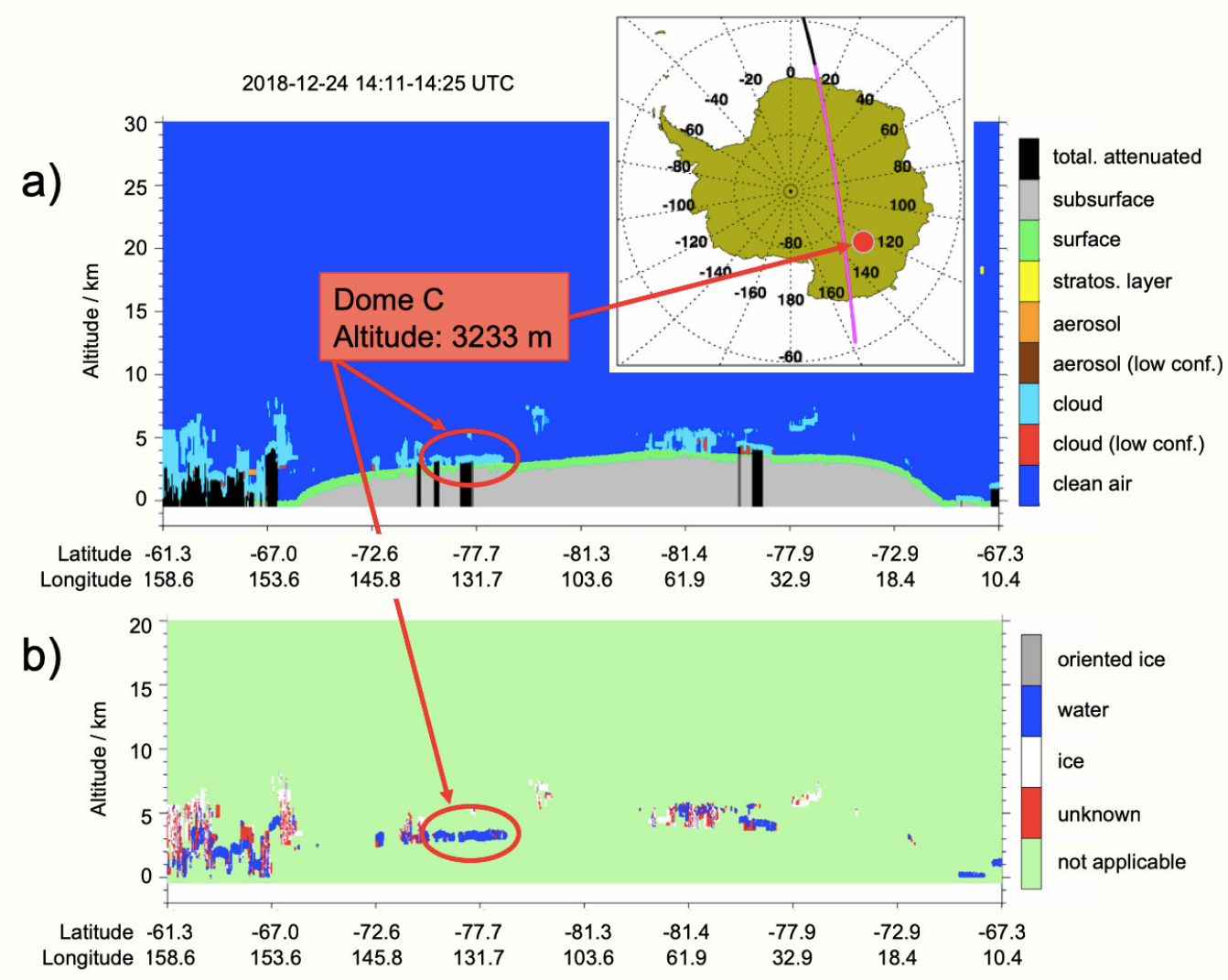

Figure S6: CALIOP/CALIPSO spaceborne LIDAR observations version V3.40 along one orbit on 24 December 2018 (14:11-14:25 UTC) in the vicinity of Dome C (75 $\left.\mathrm{S}, 123^{\circ} \mathrm{E}\right)$ : a) the Vertical Feature Mask highlighting a cloud (light blue) near the surface (red circle) and b) the Ice/Water Phase Mask highlighting a SLW (dark blue) cloud near the surface (red circle). The ground-track of the sensor (pink) has been embedded at the top of the Figure, with the location of Dome $\mathrm{C}$ marked (red filled circle). Note that the altitude is relative to the sea surface, with Dome C at $3233 \mathrm{~m}$ amsl. Figure adapted from the original image available at https://wwwcalipso.larc.nasa.gov/products/lidar/browse_images/std_v34x_showdate.php?browse_date $=20$ 18-12-24. 


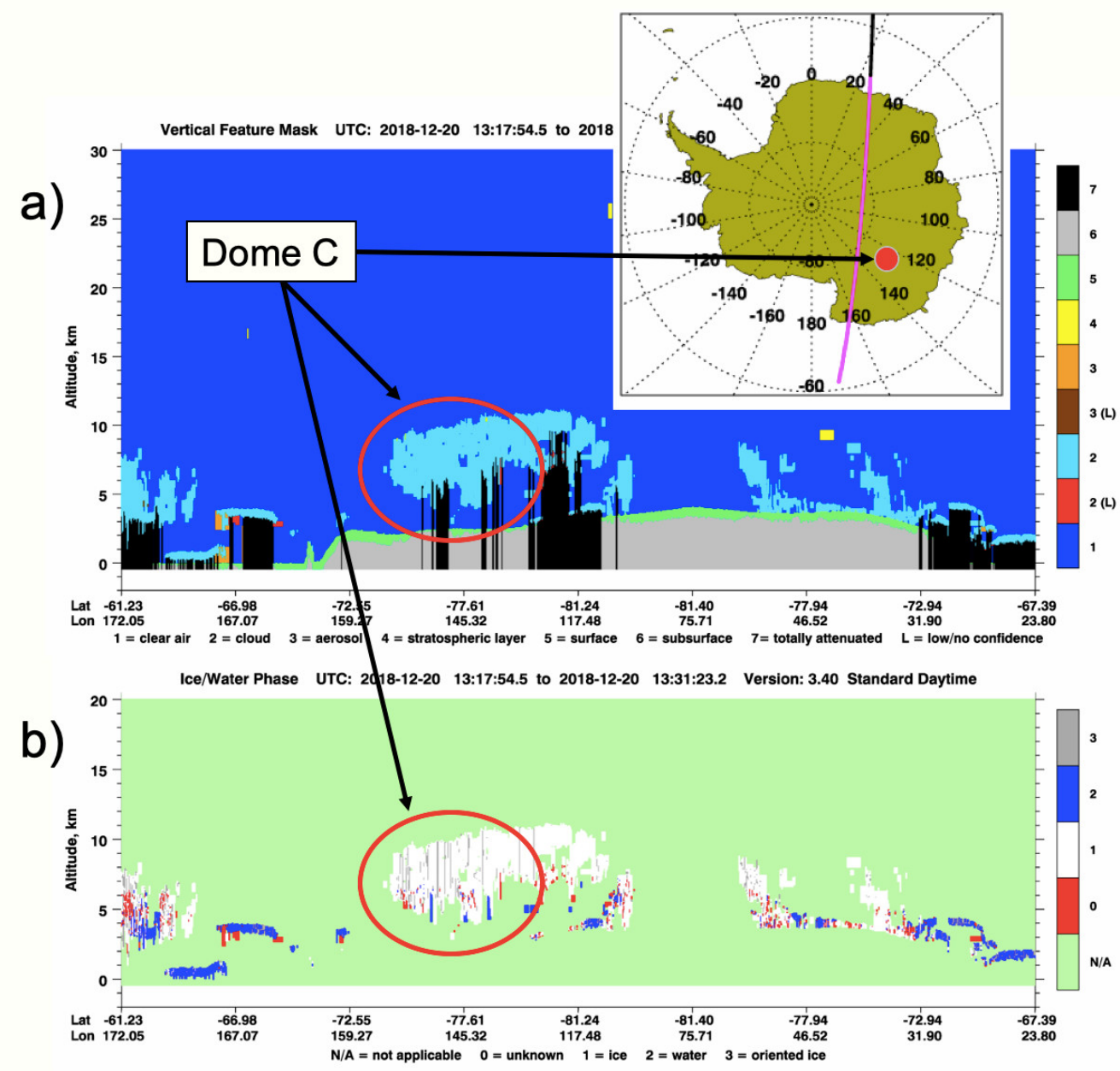

Figure S7: Same as Figure S6 but on 20 December 2018 (13:17-13:31 UTC). Figure adapted from the original image available at https://wwwcalipso.larc.nasa.gov/products/lidar/browse_images/std_v34x_showdate.php?browse_date $=20$ 18-12-20. 


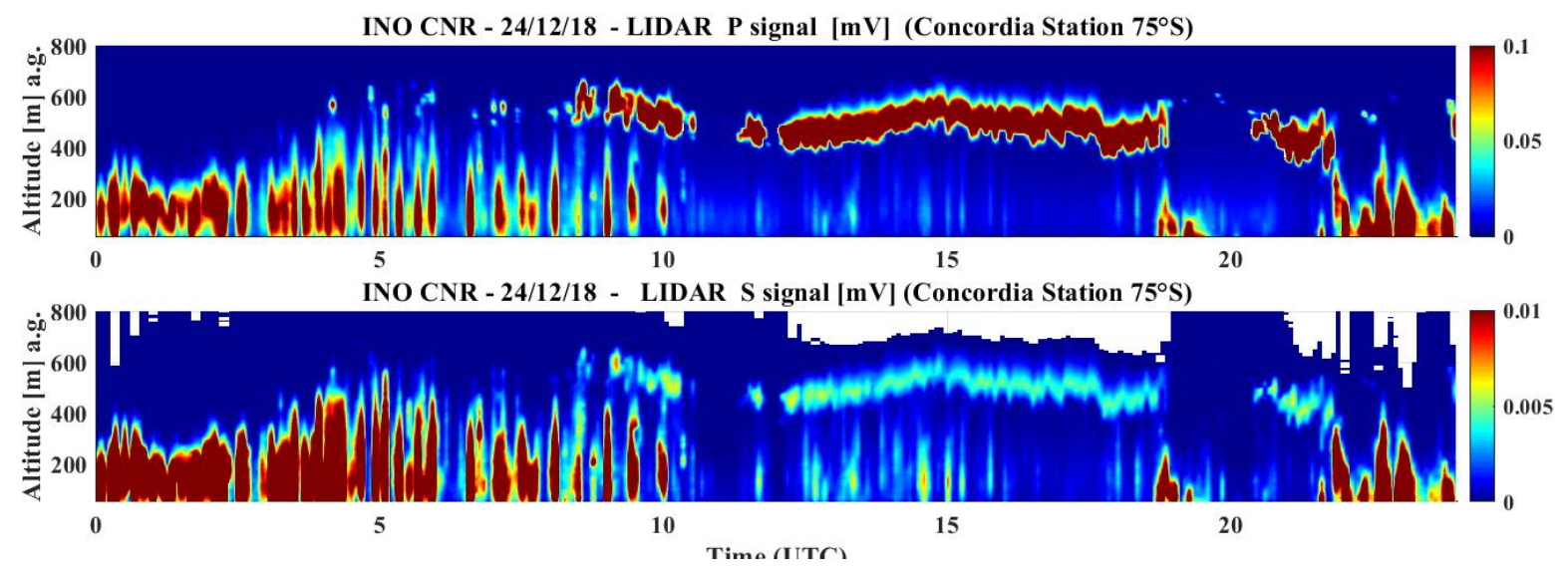

Figure S8: Time-height cross-section on 24 December 2018 (UTC Time) of the raw signals acquired by the LIDAR: (top) the LIDAR P signal $(\mathrm{mV})$ and (bottom) the LIDAR S signal $(\mathrm{mV})$. The $\mathrm{P}$ signal is the signal received with the same polarization as the laser (unpolarized component). The $\mathrm{S}$ (cross-polarized) signal is only produced by non-spherical particles. 


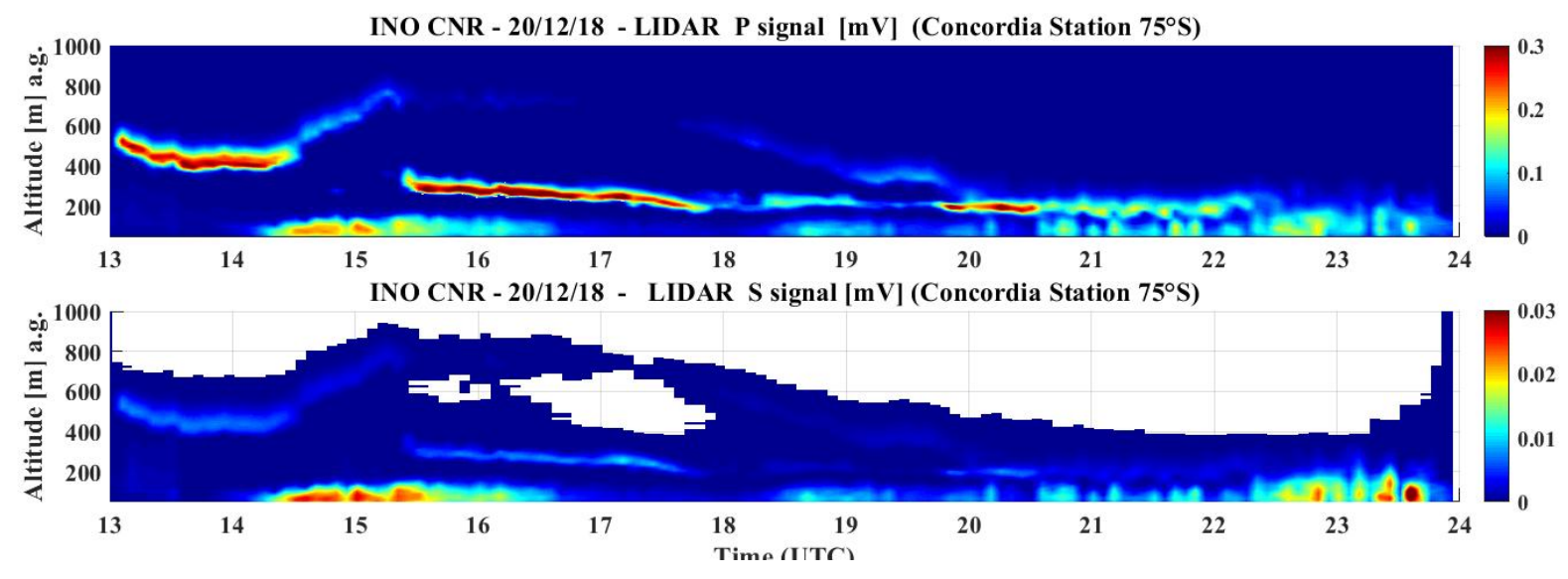

Figure S9: Same as Figure S8 but focusing on the period 13:00 - 24:00 UTC when clouds are present. 


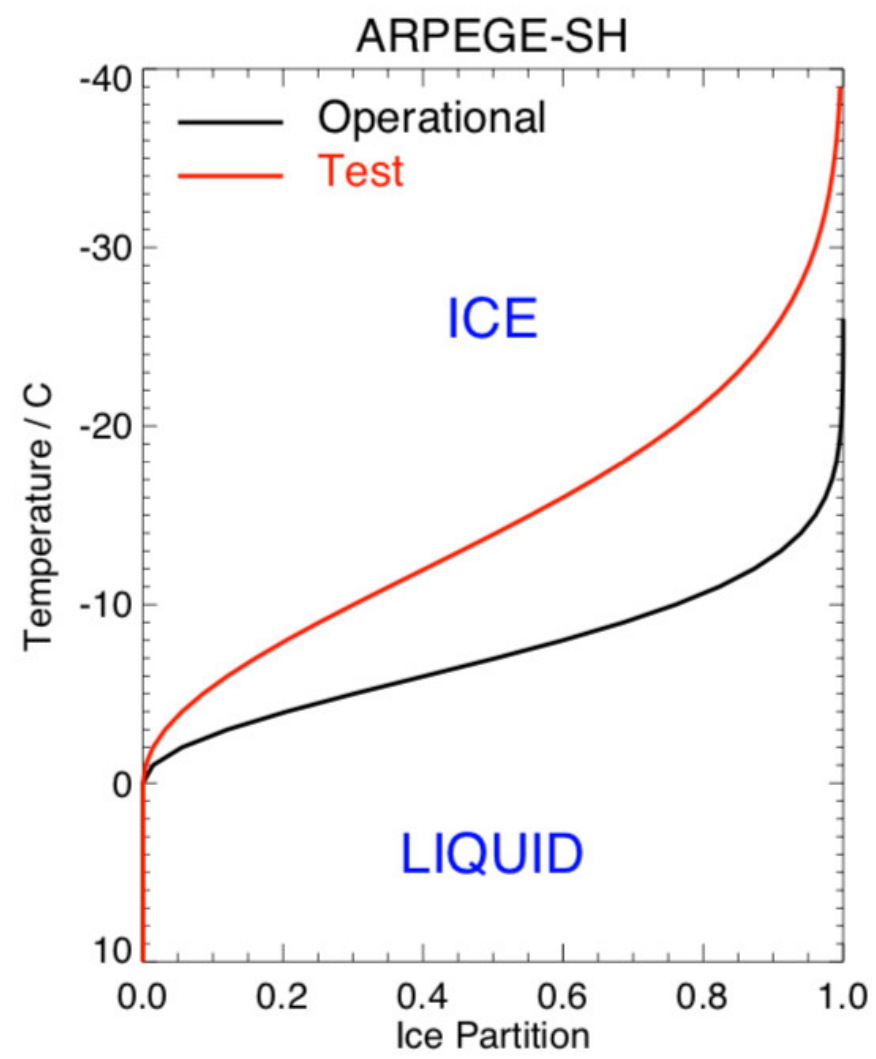

Figure S10: Ice/Liquid Water partition as a function of temperature used in the ARPEGE-SH NWP operational model (black) and in the "test" modified version (red). 


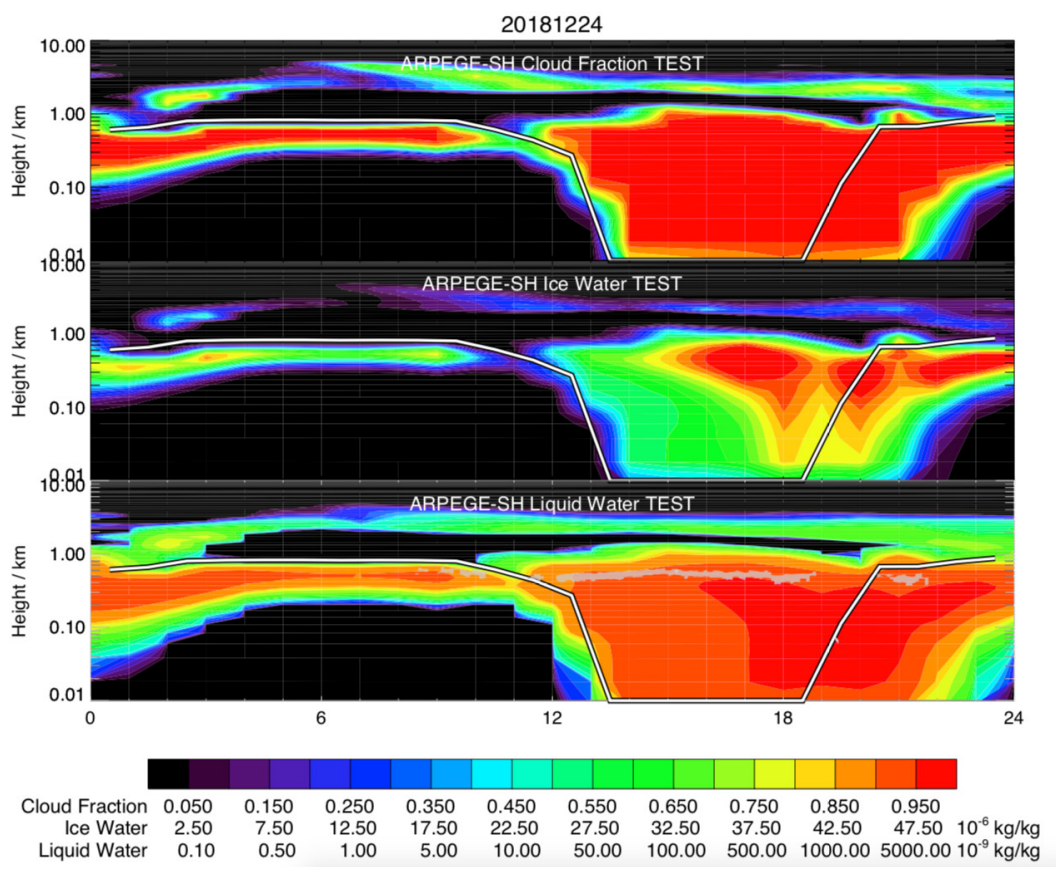

Figure S11: Time-height cross section on 24 December 2018 (UTC Time) of: a) the Cloud Fraction $(0-1), b)$ the Ice Water mixing ratio $\left(10^{-6} \mathrm{~kg} \mathrm{~kg}^{-1}\right)$ and $\left.\mathrm{c}\right)$ the Liquid Water mixing ratio $\left(10^{-9} \mathrm{~kg} \mathrm{~kg}^{-1}\right)$ calculated by the ARPEGE-SH model in test mode (new ice partition function). Superimposed to all the panels is the top of the Planetary Boundary Layer calculated by the ARPEGE-SH model (black-white thick line). Superimposed in panel c is the SLW cloud (grey area) height depth deduced from the LIDAR observations (see Fig. 2c). The colour label is consistent with is one shown on Fig. 3c. 
20181220

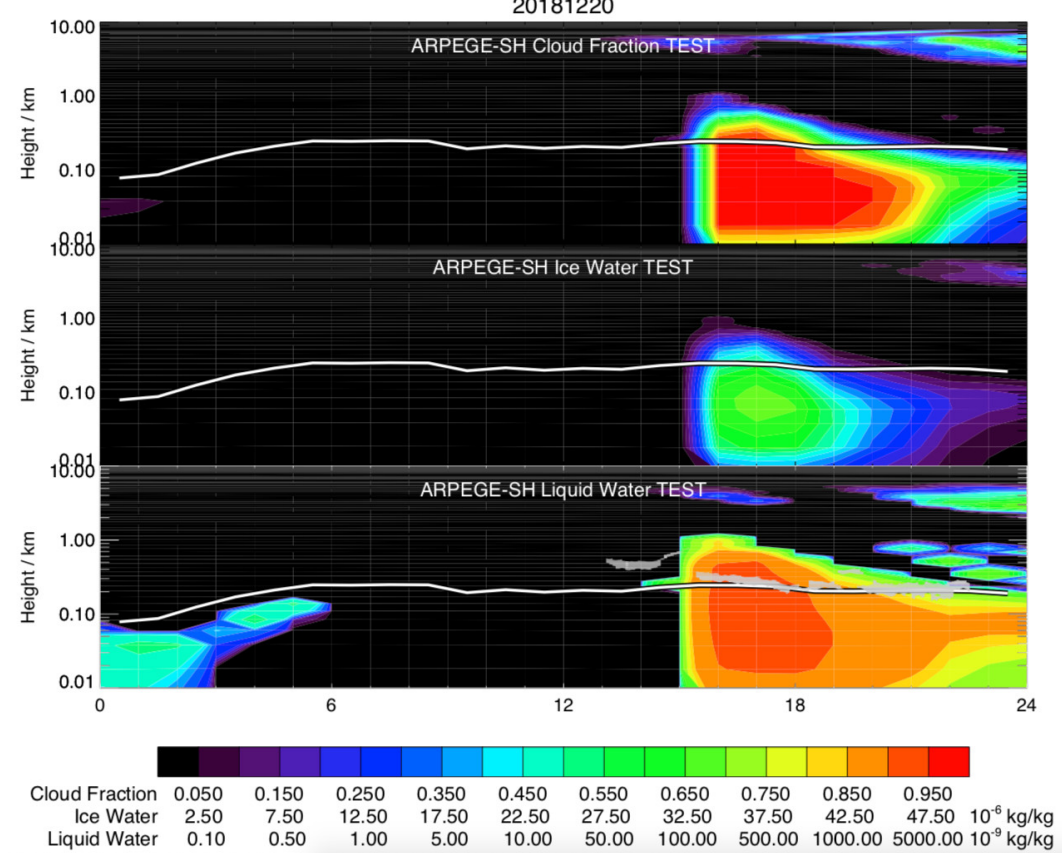

Figure S12: Same as Figure S11 but on 20 December 2018 (UTC Time). 


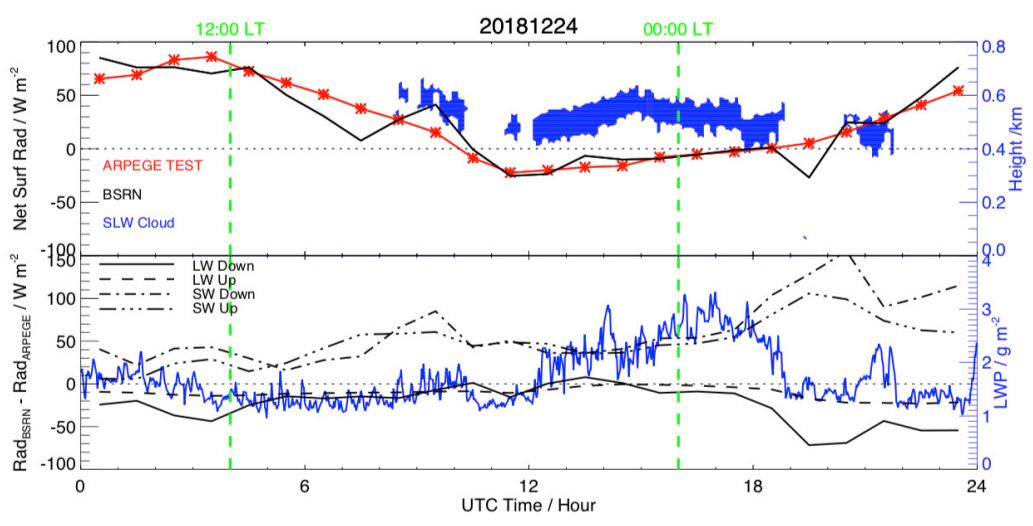

Figure S13: (Top) Diurnal variation of the net surface radiation $\left(\mathrm{W} \mathrm{m}^{-2}\right)$ observed by BSRN (black solid line) and calculated by ARPEGE-SH in test mode (red crossed line) on 24 December 2018 in UTC Time. Superimposed is the SLW cloud altitude (blue) deduced from the LIDAR. (Bottom) Diurnal variation of the difference between surface radiation $\left(\mathrm{W} \mathrm{m}^{-2}\right)$ observed by BSRN and calculated by ARPEGE-SH in test mode on 24 December 2018 for longwave downward (black solid), longwave upward (black dashed), shortwave downward (black dashed dotted) and shortwave upward (black dashed triple dotted) components. Superimposed is LWP (blue) measured by HAMSTRAD. Two vertical green dashed lines indicate 12:00 and 00:00 LT. 


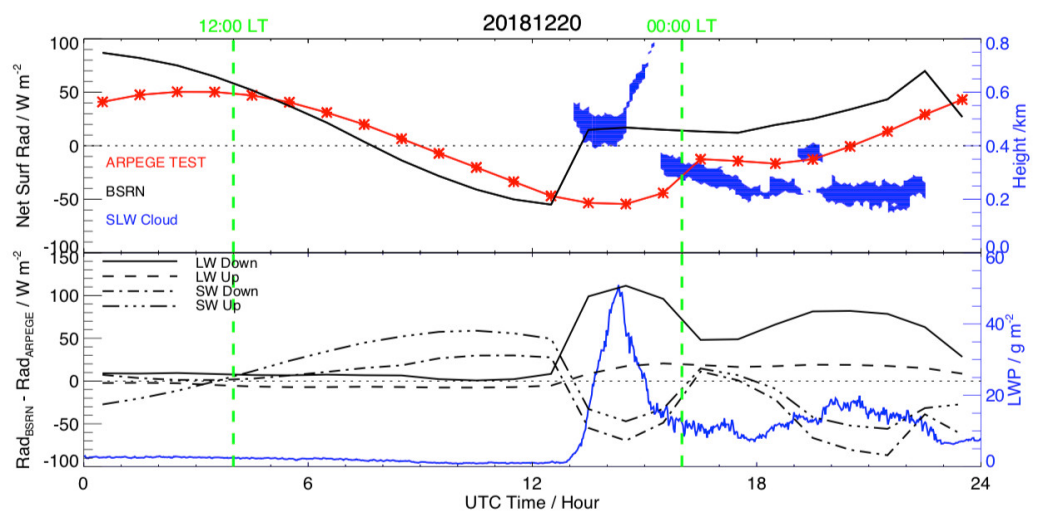

Figure S14: Same as Figure S13 but on 20 December 2018 (UTC Time). 